\section{SOME OBSERVATIONS ON SHOES}

BY'

\author{
THOMAS MARLIN, M.D., D.P.H., D.M.R.E. \\ Medical Officer in Charge of the Physiotherapeutic \\ Department, Hampstead General Hospital
}

Apart from the provision of surgical boots, the medical profession has given little consideration to the question of footwear. Sir Robert Jones advocated the prolongation of the heel on the inner side along with a wedge on the inner side of the shoe for flat feet and other conditions. Mr. Trethowan took a cast of the foot, and on this cast was fashioned a metal support to be worn* inside the shoe. Lately a heelless shoe has been marketed on the advice of a medical man, and from Canada comes a shoe bearing the name of another medical man. From time to time suggestions have been made about altering the shape of the shoe-that is, the outline-to conform more with the contour of the foot, and there has been the usual outcry against the size and shape of the heels on ladies" shoes, but little or nothing has been said regarding the foundation and construction of the shoe, and the physiological stimuli initiated by the shoe through the toes and sole of the foot.

\section{Consider the Bare Foot}

In anything which follows I may be reminded that savages do not wear shoes, to which I will simply answer that there are enough people in these islands suffering through defects in their shoes without worrying about savages in the meantime. Nevertheless, it may be convenient to approach the subject from the bare foot, and the first thing we observe is that the texture of the skin is not the same all over the foot. Over the heel, on the outer border of the sole, on the pads under the heads of the metatarsals, and over the pulp of the toes the skin is thick. On the rest of the sole-that part lying between the heel and the heads of the inner metatarsals and generally termed the long arch of the foot-the skin is thin, merging into the thin skin on the dorsum of the foot. This suggests that the weight-bearing part of the sole is that outer part first mentioned. Reflection on this leads us to doubt whether it is wise at any time to lengthen the inner side of the heel or put wedges in the inner side of the shoe, and in practice I have never yet seen a case which did not benefit by having such alteration done away with and the shoes adjusted in practically just the opposite manner. Also at this moment I might utter a protest against those manufacturers who would put all children into shoes with the heels prolonged on the inner side, for it cannot be too strongly emphasized that the skin on the inner side of the sole should be left quite free from weight bearing.

Further proof of this contention is afforded if we walk on the floor in bare feet, when we can feel for ourselves that the outer part of the sole comes in contact with the floor. If now we stand on one of those supports sold for the longitudinal arch or on a metatarsal pad or bar we realize how uncomfortable and crippling they are. And we also note how in our bare feet we avoid nails, irregularities of the ground, and anything else uncomfortable. It would seem unnecessary to mention that such discomforts should be avoided in the shoes, yet one continually finds people being crippled through want of such care. Nor would we care to walk barefooted along a rut in the road, or inside a piece of guttering with the centre of the foot and the middle toes dropping down and encouraging what is described as a dropping of the anterior arch. Yet some shoes act like this, because during wear the insoles become boat-shaped-not boatshaped in outline, but boat-shaped from side to side because they drop in the centre. This is referred to later.
The Building of a Shoe

The foundation of a shoe is the insole, and on this the shoe is built. The insole is that part of the shoe with which the sole of the foot comes into contact, and therefore corresponds to the ground when barefooted. If this is carelessly or wrongly made, if it is irregular and not smooth, or if it has bumps and hollows or sharp edges, or if during wear it develops these defects, then it can cause crippling of the feet and paralysing effects on the body generally. On the other hand, in a correctly made shoe with a proper insole, not only is fatigue of the foot and body eliminated, but the foot and toes, being able. to expand and work against the resistance of the insole, receive vital stimuli which are communicated to the rest of the body.

It is interesting to watch a shoe being built. To begin with, a last is obtained, which is a block of wood somewhat the shape of the foot, and it is important that the sole of the last should be correct, though I am afraid most lasts are defective in this respect, with the result that such defects are conveyed to the insole. To make the insole, a piece of leather is soaked in water till it is mellow, after which it is rolled or hammered out, cut to the shape desired, and then hammered to the sole of the last and kept in position with nails. When it dries the insole retains the conformation of the last.

While the insole is still in position the upper (with its lining) is fitted over the last and sewn to the insole, and to the edge of the upper is sewn the welt. The welt we are all familiar with; it is a strip of leather about an eighth of an inch thick and half an inch to threequarters of an inch broad, running round the sole as far as the heel. It thus forms a backing to which the outer sole can be sewn without taking the stitches through the upper.

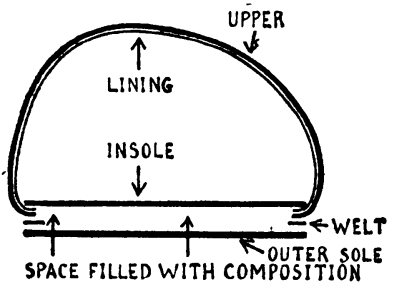

It will be observed that in such an arrangement a space is left between the insole and the outer sole ; it is shown diagrammatically in the figure. Manufacturers fill this space with a composition such as sawdust and glue, but in a very short time the heat and moisture from the foot soften this composition, so that it becomes worked into bumps, and allows the insole to fall down in the centre, thus causing the boat-shaped condition referred to above. Manufacturers must find a way of overcoming this.

In front of the heel is the waist, and it is important that this should not break or sag and allow the cuboid bone to drop. It is possible to achieve this by leather alone, and I am strongly against the steel or wooden shank pieces which are so much used. They are so rigid that they paralyse the foot, yet they are fitted in some of the most expensive proprietary shoes. Since I have been advocating that the outer part of the foot should be supported I have seen an American shoe advertised as built to "support the vital outer arch of the foot," but in this shoe are metal strips running through from the heel, making the shoe quite rigid.

Rigidity must not be confused with the resistant force of the insole which has already been mentioned. This resistance is partly due to the resilience of the insole itself, but is also due to the pull between the upper and the insole. For this reason there is very little resistant force in sandals, and as rubber and canvas have not the resilience of leather there is no resistant force in shoes 
made of these materials. Moreover, shoes made on the same last by different workmen may vary in an extraordinary manner: some may be full of life, and others quite dead, according to the way they have been lasted.

With respect to the outline of the shoe there is not so much ground for complaint. One can get such a variety to choose from-narrow shoes, broad shoes, pointed or blunt toes, $\mathrm{cr}$ with a straight inner border. The latter style is supposed to prevent the condition of hallux valgus ; but people with this disorder need not be compelled to wear ugly shoes, for it is possible to give them pointed shoes and still provide room inside for the enlarged joint.

\section{The Problem of Heels}

This does not worry men so much as women. Girls' shoes have flat heels with a good superficial area in contact with the ground. But at some peculiar transitional period in their lives the girls suddenly appear before us in ladies' shoes, with heels of varying heights and diminished superficial area. Now, however much we may wish we could alter these matters, they seem to be beyond our control, because the ladies are determined to have their high heels. And the practical fact is that high heels seem to be necessary for about 90 per cent. of our womenfolk - they feel better in high heels than in low heels. Instead of simply condemning high heels it would be better for us to try to obtain a sensible heel and still provide ladies with the height they want. I don't mean that spindle-shaped heels three inches high should be worn, but I do not object at all to one and a half inch or even two inch heels. Very pointed heels are bad because of the difficulty of balancing, and we must also guard against heels which come so far forward that the wearer is all the time tending to overbalance backwards.

\section{Medical Bearings of Shoe Construction}

In this article I have merely tried to present some of the problems in the making of shoes in which we, as medical men, have an interest, the chief point being the construction and function of the insole. This must be so fashioned on the last and presented to the sole of the foot in the shoe that the outer part of the foot strikes the insole first and the inner arch is left quite free. $W_{\text {:. }}$, n this is so, then the foot takes its normal spring in the shoe. But as shoe manufacturers have for years forgotten or neglected some of the things I have mentioned, many foot troubles have developed: rigid joints, flat-foot, contracted toes, contracted tendons, minor deformities, want of tone in the muscles, limpness and deadness of the toes so that they fail to spread and work against the insole, dropping of the heads of the metatarsals so that people are walking on them and producing all manner of nervous disturbances. And many of these changes in the feet seem to be correlated with different organ; of the body, disorders of these organs being influenced by a correction of the shoes.

To ro into this question and to discuss how certain disorders reflect themselves in the feet and shoes, and how to recognize such signs, would occupy much space, because the subject is very complicated. For the same reason it would be impossible here to show how corrections are made in existing shoes; but in the main we might say that adjustments are generally made between the insole and outer sole, and the wedges pared at the edges so that they are not apparent to the casual observer, and the shoe mender should as far as possible deal with any defects which have appeared in the insole. Finally, the soles should be sewn and not nailed, because, apart from any other damage caused by nails, they destroy the welt Ind make further repairs more difficult and unsatisfactory.

\section{INTERNATIONAL NEUROLOGICAL CONGRESS COPENHAGEN, AUGUST, 1939}

The third International Neurological Congress will be held in Copenhagen from August 21 to 25, 1939, under the presidency of Professor Viggo Christiansen. The following is an outline of the arrangements so far as these are now settled.

An informal meeting at the Restaurant Nimb on the evening of Sunday, August 20, will be followed by the official opening of the congress at the Rigsdag Building on August 21 at 9.30 a.m., after which there will be a discussion on the endocrine-vegetative system, with special reference to neurology, under the chairmanship of Professor L. van Bogaert and Professor $\mathrm{H}$. Pette. The official rapporteurs for this - discussion are: Sir Henry Dale (London), Dr. Laruelle (Brussels), Professor Fulton (New Haven), Dr. O. Foerster (Breslau), and Dr. Forsberg (Oslo). In the evening there will be a reception by the Corporation of Copenhagen at the Town Hall.

On August 22 there will be a discussion on heredofamilial disease, especially from the genetic aspect, under the chairmanship of Professor G. Guillain and Professor V. M. Buscaino. The rapporteurs are Professor B. Sachs (New York), Professor André Thomas (Paris), Professor JonescoSisesti (Bucarest). Professor Curtius (Berlin), and Professor Schaffer (Budapest). For August 23 no scientific business has been arranged, but there will be excursions to Frederiksborg Castle, Hillerd, Kronborg Castle, etc. On August 24 short papers will be read on various neurological and neurosurgical subjects, followed by the official banquet in the evening. The subject for discussion on August 25 is " Neurological Aspects of the Avitaminoses with Special Reference to the Peripheral Nervous System," under the chairmanship of Professor Monrad-Krohn. The rapporteurs are Sir Edward Mellanby (London), Professor G. C. Riquier (Pavia), Dr. J. S. Wechsler (New York), Dr. D. McAlpine (London), and Dr. H. P. Stubbe Teglbjaerg (Copenhagen). In the evening a reception will be held at the King's summer residence, Fredensborg Castle.

Applications for active membership from neurologists in Great Britain should be made to the Secretary of the British National Committee, Dr. Macdonald Critchley, 137, Harley Street, London, W.1, to whom the subscription (40 Danish kroner) should be paid. Associate membership is open to non-professional persons, men and women, interested in the congress, subscription 20 Danish kroner. Papers bearing on one of the three main subjects or on any aspect of neurological medicine are invited. The maximum time allotted is ten minutes. Titles of communications, together with an abstract not more than 150 words long, should be sent to the Secretary of the British National Committee by April 1, 1939. Arrangements for travel and hotel accommodation are in the hands of the American Express Company, 6, Haymarket, London, S.W.1 (Telephone: Whitehall 4411).

H. Ensing (Nederl. Tijdschr. Geneesk., 1938, 82, 5381) records his observations on seventy-nine cases of actinomycosis treated at the Gröningen Academy Hospital during the last thirty years. The localization of the disease was as follows: neck and jaw, forty-six cases; thorax and lungs, two ; abdominal wall and abdominal organs, thirty-one. Of the fifty-one male adults thirty-one were agricultural labourers, while the occupation of the remaining twenty brought them much less in contact with the soil (clerks, factory workers, and others). The ages of the patients ranged from 15 to 35 . There were fifteen adult women patients, and of thirteen patients under 20 seven were males and six females. In more than half the cases infection took place by the buccal mucosa. In twenty-three of the thirty-one cases of abdominal actinomycosis the primary localization was in the ileo-caecal region, in two in the sigmoid, and in one in the rectum, while in the other five the primary focus could not be discovered. Recovery took place in 88 per cent. of the cases in which the neck and jaws were involved, and in 28.5 per cent. of the abdominal cases. 